\title{
The recent trend of e-waste recycling and rare metal recovery in Japan
}

\author{
H. Itoh \\ Nagoya University, EcoTopia Science Institute, Japan
}

\begin{abstract}
The efficient resource circulation of rare metals is one of the most important economic and political issues in an industrialized society. Rare and noble metals in e-wastes should be collected separately, treated by advanced processes, and then supplied as raw materials for high technology material production. In Japan, the home appliance recycling law was established in 2001 for recovery of base metals (Fe, $\mathrm{Al}, \mathrm{Cu}$, etc.), plastics and flons, subject to large electrical appliances such as TV's, air conditioners, washing machines and refrigerators. After a long-term discussion, the recycling law of small household electrical appliances has been legislated in 2013 for the recovery of rare or noble metals in cellular phones, digital cameras, PC's, printers, DVD players, game consoles, etc. On the other hand, there are many sorts of industrial wastes containing rare metals. Typical waste categories are classified as (1) effluents from plating plants or wastewater treatment industries, (2) e-wastes from electronic substrates, household appliances, and many kinds of batteries, (3) automobiles, tools and structural materials and (4) wastes from incinerators, melting furnaces and power stations. However, a small amount of rare metals in these industrial wastes has not been extracted intentionally, but usually disposed at landfill sites. The new concept of "rare metal recovery complex" (RMRC) is now derived in order to collect the wastes containing rare metals and give them mechanical, physical and chemical treatments in a systematic complex plant. We refer to this infrastructure in Japan as "urban mining", which enables the minimum use of energy and reagents required for the crushing/shredding, separation and purification processes of rare metals. The present paper introduces the recent progress of rare metal recycling in Japan in the context of RMRC.

Keywords: e-wastes, rare metals, urban mining, rare metal recovery complex.
\end{abstract}




\section{Introduction}

E-wastes range from large electrical appliances like a refrigerator to small household electrical appliances (SHEA) like a cellular phone. They are generally composed of base metals (Fe, $\mathrm{Al}, \mathrm{Cu}, \mathrm{Zn}$ ), rare/noble metals (W, Co, Ni, Ta, Nd, $\mathrm{Dy}, \mathrm{Au}, \mathrm{Ag}, \mathrm{Pt}$, etc.), glass and plastics (PP, PE, PS, ABS), sometimes containing hazardous organic or metallic elements/compounds. Appropriate treatments of e-wastes are needed in order to avoid environmental pollution and to recycle precious resources. In particular, the recovery and reuse of noble or rare metals in e-wastes are increasing its importance in an industrialized country. They are facing the difficulty to import virgin metals from developing countries, and to supply raw metals at low prices to the production industry.

Technological innovation for rare metal recycling is essential for attaining efficient circulation of materials as well as the formation of a systematic supply chain in the material vein system. The present status of recycling technology of typical rare metals in e-wastes is reviewed in the present paper in addition to the legal framework of e-waste recycling in Japan.

Comprehensive understanding and perspective for urban mining of e-wastes are required to attain efficient recovery of rare metals in municipal and industrial wastes. A new concept of rare metal recovery complex is proposed to promote the recycling rate of each metal and the refinery-type recovery system of most kinds of rare metals in e-wastes.

\section{Legal framework of e-waste recycling in Japan}

One of the distinctive features of waste management in Japan consists in the completely different collection system of municipal waste and industrial waste. E-wastes discharged from the household refuse, for example, are legislated to be collected by the municipal government, while the e-wastes discharged from industries are to be collected by exclusive collecting companies authorised by the government.

In view of a brief history of waste management in Japan, a remarkable change in wastes management conception occurred at the beginning of the $21^{\text {st }}$ century from "disposal for sanitation" to "recycling for resources circulation". Many kinds of recycling laws were legislated or enforced, e.g. the container and packaging recycling law (1997), the home appliance recycling law (2001), the construction material recycling law (2000), the food recycling law (2000), the end-of-life vehicle recycling law (2002), and the law for the promotion of effective utilization of resources (2001). Since then, 3R thinking for reduce, reuse and recycle has been pervaded all over Japan. So-called "MOTTAINAI" (a sense of regret concerning waste) is frequently and naturally spoken by Japanese people to promote recycling of food, material and energy.

Especially, a rapid requirement for recycling of rare meals has increased as a turning point of rare earth crises in 2010. Large and small household appliances have become known as "urban mines" in contrast to natural mines, because rare metals are stocked in a large amount of e-wastes in Japan. 


\subsection{Recycling law of large home appliances}

The home appliance recycling law was enforced in 2001 in Japan with confined to four large-sized appliances of $\mathrm{TV}$, air conditioner, washing machine, refrigerator. The main purpose of this law was to prohibit an illegal dumping at deserted area, and to protect against environmental pollution by hazardous materials such as flons in the compressor, leaching toxic metals and decomposed resin. Another purpose was to recover plastic materials and base metals in the cabinet and to reuse them for horizontal or cascade recycling. The consumers are obligated to pay the recycling charge in case of dumping or replacing home appliances, while the retail distributors should collect and deliver them to the manufacturers, who are obliged to recycle them by their own treatment technologies based on the concept of extended producer responsibility.

This legislation was effective to inhibit the illegal damping and to recycle the base materials in the scraps. In addition, it helped to reduce the amount of wastes to be landfilled at the public site for final disposal. The recycling rate of the four kinds of appliances was $85-95 \%$ in 2012 according to the statistics by Ministry of Environment, Japan. However, precious or rare meals in electronic devices or electric components have been less extracted from these appliances, and recycling of rare metals could not be attained except noble metals $(\mathrm{Au}, \mathrm{Ag}, \mathrm{Pt}$, etc.). Furthermore, recycling of rare metals in small household appliances including personal computers (PC) has not been regulated legally, but entrusted to the current market.

\subsection{Recycling law of small household electrical appliances}

There are many sorts of small household electrical appliances (SHEA), e.g. cellular phone, audio equipment (portable music player, MD \& CD players), digital/video camera, PC including tablet computer, printer, telephone/facsimile set, calculator, DVD player, game console, electric fan, hand blower, vacuum cleaner, rice cooker, and their accessories. These appliances contain more precious metals (noble and rare metals) compared with the four items of large electrical appliances. Moreover, the consumption period is rather short due to the appearance of alternative or innovative products in the market. Therefore, the necessity for recovery and recycling of precious metals from the spent small appliances has been increasing in Japan.

On the other hand, the above e-wastes have been exported to east/south Asian countries from Japan as "second hand home appliances". It is reported by the mass-media that they are dismantled and treated under the worst working environments, so that human diseases and local air/water/soil pollution have spread among the operators and residential area. Considering these circumstances, domestic circulation of e-wastes in Japan should be accomplished so as to prevent such serious problems in Asia.

After a long term discussion at the wastes and recycling sub-committee, Central Environmental Council of Japan, the model projects for recycling SHEA were implemented from 2009 for 3 years. One of the greatest issues is how to collect SHEA from the consumers, who pay for collection and transportation, 
and who is responsible for security and robbery risks. Table 1 shows the summarized results attempted for collection of spent SHEA in representative seven areas in Japan. In the table, the box collection system is mostly adopted which enables people easy throwing the spent SHEA into the assigned boxes at public office, supermarket, electronics retail store or DIY store. Station collection is found very convenient for residents, because recycling station of used paper, cardboard, etc. is very popular in Japan. Pick-up collection is to pick up the SHEA from the non-flammable refuse collected in the large scale gasification melting furnace installed by the local government. Group collection by hand to hand delivery is the most reliable and safe system, though it needs a high level of awareness of people for e-waste recycling. Event collection method is also popular and adopted frequently, but is difficult to hold the event consecutively.

Table 1: Collection system of spent household electric appliance.

\begin{tabular}{|c|c|c|c|c|c|c|c|c|}
\hline \multirow{2}{*}{$\begin{array}{c}\text { Collection } \\
\text { system }\end{array}$} & \multicolumn{7}{|c|}{ Local governments } & \multirow{2}{*}{ Remarks } \\
\hline & $\begin{array}{l}\text { Akita } \\
\text { Pref. }\end{array}$ & $\begin{array}{c}\text { Ibaraki } \\
\text { Pref. }\end{array}$ & $\begin{array}{l}\text { Fukuoka } \\
\text { Pref. }\end{array}$ & $\begin{array}{l}\text { Tokyo } \\
\text { Metro. }\end{array}$ & $\begin{array}{l}\text { Nagoya \& } \\
\text { Tsushima }\end{array}$ & Kyoto & Minamata & \\
\hline Box & 0 & 0 & O & 0 & 0 & 0 & O & $\begin{array}{l}\text { - The most available collection } \\
\text { system in every municipality } \\
\text { - Security and robbery risks are } \\
\text { concerned issues }\end{array}$ \\
\hline Station & & & 0 & & $\mathrm{O}$ & & $\mathrm{O}$ & $\begin{array}{l}\text { - Easy to access and convenient } \\
\text { for most residents } \\
\text { - Robbery risk exists in case of } \\
\text { no guard }\end{array}$ \\
\hline Pick-up & 0 & 0 & 0 & & & 0 & & $\begin{array}{l}\text { - Easy to deliver and discard } \\
\text { - Needs to employ pick-up } \\
\text { persons in the stock yard }\end{array}$ \\
\hline Group & & & & & 0 & $\mathrm{O}$ & & $\begin{array}{l}\text { - The most reliable collection } \\
\text { by hand to hand delivery } \\
\text {-Volunteer activities by citizens } \\
\text { are needed }\end{array}$ \\
\hline Event & 0 & 0 & 0 & 0 & & 0 & 0 & $\begin{array}{l}\text { - Informative and enlightening } \\
\text { effects for inhabitants } \\
\text { - Rather difficult to hold events } \\
\text { consecutively }\end{array}$ \\
\hline
\end{tabular}

O Shows the collection system which was applied by each local government.

The recycling law of SHEA was enacted in August, 2012, and enforced in April, 2013, based on a successful practice of the model projects. The main framework of this legislation consists in the voluntary collection activity by the local governments (municipalities or prefectures), and the subsequent intermediate treatments (mainly transportation, dismantling, shredding, sorting, and mechanical separation/enrichment) by the companies approved by the Ministry of Environment (ME) and Ministry of Economy, Trade and Industry (METI), Japan. Then, refining and purification of these enriched metals are carried out by metallurgical and chemical treatments at the urban mining companies, which is the final stage of recycling of SHEA. 


\section{Progress of recovery technology of rare metals in Japan}

The treatment of industrial solid wastes containing rare metals is not covered by the above legislation, but they should be treated in accordance with waste disposal law for industrial wastes in Japan. A large amount of rare metals has been discharged as the process wastes of many manufacturing companies, and the most part has been landfilled except special cases for recycling. The intermediate scraps as well as SHEA are sometimes called actual urban mine.

Figure 1 shows the material flow and treatment technology used for rare metal recycling. The first step is to collect the municipal and industrial wastes containing rare metals from consumers and enterprises. Voluntary activity by citizens and the organized activity by local governments play an essential role to increase the collection rate of rare metals in e-wastes. Moreover, the motivation to increase the recycling rate of resources enables the manufacturers to collect more rare metals from their own industrial waste. Thus collected wastes are dismantled and crushed roughly at the intermediate treatment company. Hand sorting is sometimes superior to mechanical classification. This first separation process is very important, because it decides the subsequent recycling rout of each rare metal component. In fact, later separation of the mixed wastes with high entropy state needs much energy and cost, so that environmental load for recycling will increase.

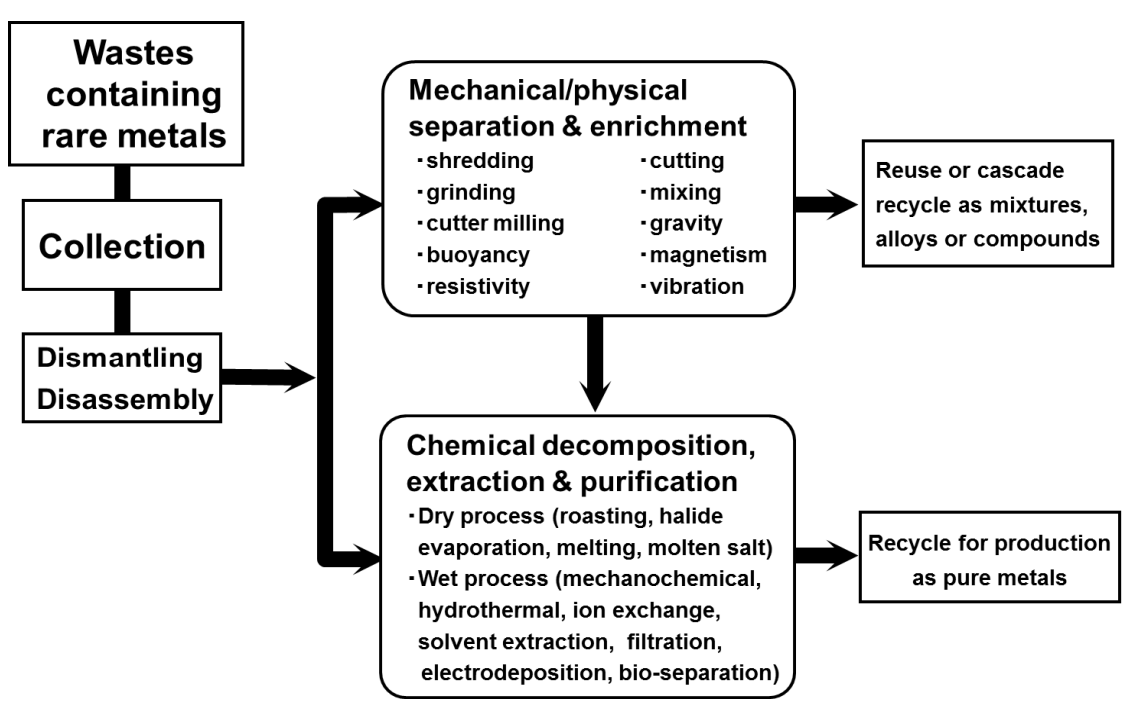

Figure 1: Material flow and technology used for rare metal recycling.

The next stage of recycling is to separate and enrich rare metal in the pretreated wastes more precisely by mechanical or physical treatments. Many kinds of equipment for shredding, cutting, grinding, mixing or milling are used 
as mechanical treatment in which liberation of the multi-phase waste into each component is a key-technology in the recent progress. Enrichment of rare metal is also carried out by physical treatments using vibration separation, gravity separation, buoyancy separation, magnetic separation or eddy current separation. Some treatments have been adopted in the traditional mining process. Others are developed recently for enrichment of rare metals in urban mine.

The final stage of rare metal recycling is smelting or chemical treatment for decomposition, extraction and purification. Advanced techniques by roasting, halide evaporation, melting and molten salt treatment are developed as dry processes. Wet process includes the mechanochemical treatment, hydrothermal treatment, ion exchange, solvent extraction, filtration, electrodeposition and bioseparation.

The rare metals recovered by the above processing can be supplied to production companies as recycled raw materials with comparable quality to virgin raw materials. Japanese recent progress in urban mining technology of typical e-wastes and industrial solid wastes will be described in the subsequent sections. It is still the target of the research and development for higher recycling rate and more efficient recovery of rare metals with low cost and low environmental load.

\subsection{Neodymium magnet}

Neodymium magnet was invented by Dr. Segawa in 1984. Its main composition is $\mathrm{Nd}_{2} \mathrm{Fe}_{14} \mathrm{~B}$, which is plated with $\mathrm{Ni}$ and $\mathrm{Cu}$ for preventing oxidation, and is added with dysprosium (Dy) for increasing heat resistance of the magnet. Owing to the highest maximum energy product, this magnet has expanded its application to the drive motors of large/small electrical appliances, HV/EV vehicles, medical equipment, wind power generator, etc.

Worldwide rare earth crisis occurred in 2010 because of the export restrictions in developing countries. The cost of $\mathrm{Nd}$ and Dy jumped steeply, and the import of these metals became difficult in most industrialized countries. Recycling and reuse of rare earth metals were required along with the reduction of rare earth input in magnet production. Japanese government decided to subsidize the research and development for recycling of rare earth metals as the supplementary budget in 2011 fiscal year.

The recycling steps of neodymium magnet consist of collection, separation, demagnetization, crashing, and dry/wet smelting. Special automatic separation technique of the magnets from the compressor motor was developed by Mitsubishi Material Co., Ltd., Japan. As a dry recovery process, Takeda et al. [1] reported the separation procedure of $\mathrm{Nd}$ and $\mathrm{Dy}$ in the neodymium magnet by the combination of molten salt extraction and chloride evaporation. The magnet scrap was heated at $1,000^{\circ} \mathrm{C}$ with $\mathrm{MgCl}_{2}$, and the molten salt reaction enabled the separation of liquid phase of $\mathrm{Nd} / \mathrm{Dy}$ chlorides and $\mathrm{Mg} / \mathrm{MgCl}_{3}$ from solid phase of Fe-B. Then, the molten salt mixtures were separated by vacuum distillation according to the thermodynamic properties of each chloride. Finally, the separated metal chlorides were reduced to respective metals. 
Hydrothermal recovery process of $\mathrm{Nd}$ from neodymium magnet was developed by the present authors [2] as shown in fig. 2. Nickel plated magnet was firstly treated in the aqueous solvent mixed with $\mathrm{HCl}$ and oxalic acid under mild hydrothermal conditions. Solid precipitate of $\mathrm{Nd}_{2}\left(\mathrm{C}_{2} \mathrm{O}_{4}\right)_{3} \cdot \mathrm{xH}_{2} \mathrm{O}$ was recovered with the yield as high as $99 \%$. This product was calcined at $800^{\circ} \mathrm{C}$ to form $99.8 \% \mathrm{Nd}_{2} \mathrm{O}_{3}$ powder. The $\mathrm{pH}$ of residual solvent was subsequently adjusted at 7.0 to remove $\mathrm{Fe}_{2} \mathrm{O}_{3}$ and $\mathrm{NiO}$ precipitates. Finally the solution containing only boron was hydrothermally treated again with $\mathrm{Ca}(\mathrm{OH})_{2}$. Stable boron ion was precipitated as parasibirskite mineral, $\mathrm{Ca}_{2} \mathrm{~B}_{2} \mathrm{O} \cdot 5 \mathrm{H}_{2} \mathrm{O}$.

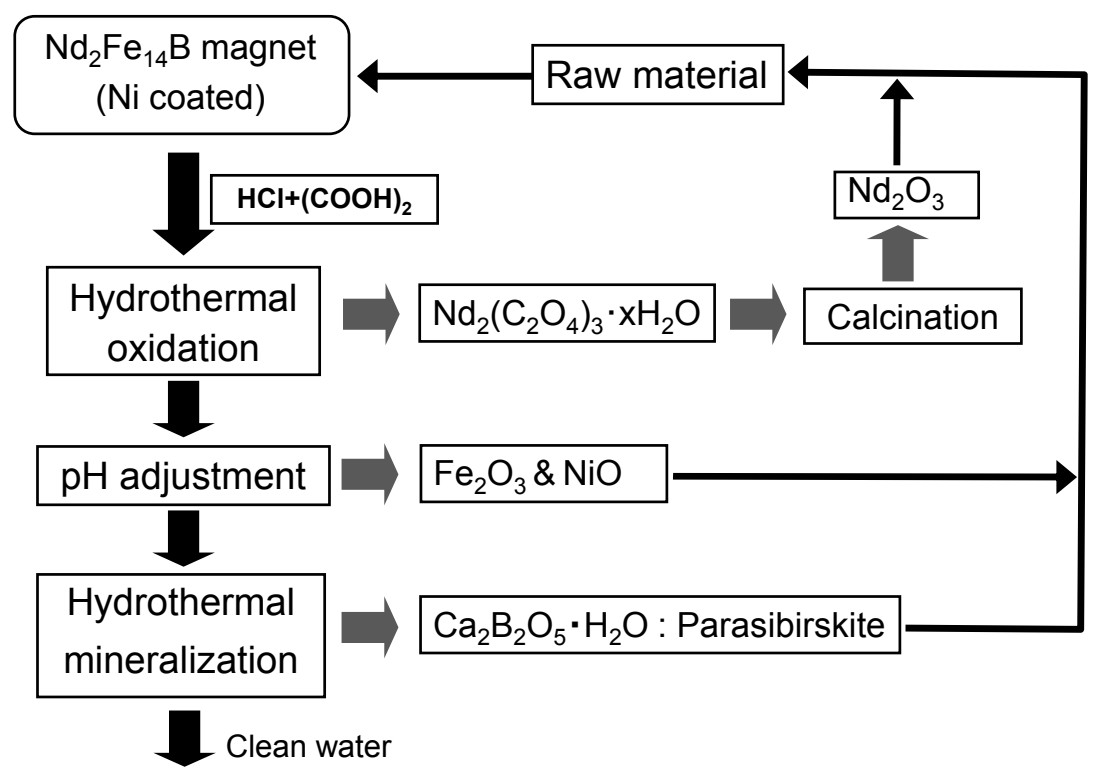

Figure 2: Hydrothermal recycle process of rare earth magnet.

\subsection{Printed circuit board}

Printed circuit board (PCB) is a generic name for the electronic substrate mounted by the many components such as IC/LSI chip, resistor, capacitor, thermistor, crystal oscillator, etc. Main board is composed of epoxy resin containing glass fibre and flame retardants $(\mathrm{Br}$ or $\mathrm{Sb})$, which is attached with copper wiring circuit. Therefore, PCB contains many kinds of metals, e.g., noble metals ( $\mathrm{Au}, \mathrm{Ag}, \mathrm{Cu}$ ), PGM ( $\mathrm{Pt}, \mathrm{Pd}$, etc.), and rare metals ( $\mathrm{Ta}, \mathrm{Ni}, \mathrm{Co}, \mathrm{W}, \mathrm{Ga}, \mathrm{Sb}$, $\mathrm{Pb}$, etc.) as well as resin and glass. Conventional goal for $\mathrm{PCB}$ recycle has been to recover noble metals only, because they are in good demand at high price. However, rare metal recycling has been technically difficult and less profitable, so that they have been landfilled as residue after the recovery of noble metals. 
In order to recover rare metals from PCB, the liberation of each component is important in the crushing or grinding process, and the enrichment of rare metal should be attained by physical separation techniques. New technologies have been developed recently focusing on the enrichment of rare metals by novel comminution, electrical pulse disintegration or underwater explosion [3].

\subsection{Tantalum capacitor}

Tantalum has the Clarke number as low as $1 \mathrm{ppm}$. The cost of tantalum metal is increasing with the increase in demand for high dielectric constant capacitor in SHEA. This results in higher interests in recycling of tantalum from electronic devices. Tantalum capacitors are installed on PCB of computer, cellular phone, digital camera, etc. The liberation of tantalum capacitor from PCB with mounted parts is indispensable to increase Ta concentration in the treated matter. Ono and Fujita [4] succeeded to recover tantalum from PCB by underwater explosion for capacitor liberation, and the subsequent heat treatment and eddy current separation for tantalum enrichment. Oki [5] developed an enrichment process of tantalum capacitor by mechanical treatment (crushing and sieving) and physical treatments (magnetic and air stream separation) of PCB with mounted parts.

\subsection{Lithium ion battery}

Cobalt, one of the typical rare metals, is an important constituent of cemented carbide tool, special alloy steel, magnet (Sm-Co or Al-Ni-Co), hydrogen storage alloys, and lithium ion battery which will be loaded in near future in large amount on automobiles and power storage facilities. Therefore, stable supply of Co to manufacturing industries is a crucial issue in Japan. Considering the expanded demand for lithium ion battery, the recovery and recycling of cobalt is increasing its importance.

Lithium ion battery is generally composed of cathode, anode, and nonaqueous electrolyte. Though cathode active material has been mainly $\mathrm{LiCoO}_{2}$, the ternary composite material $\mathrm{Li}(\mathrm{Co}, \mathrm{Ni}, \mathrm{Mn}) \mathrm{O}_{2}$ is used recently to reduce expensive Co content. The cathode is prepared by pasting the above active material onto aluminium foil with PVDF and carbon black. On the other hand, graphite or carbonaceous material is used as anode. Electrolytic material is a mixture of lithium salt $\left(\mathrm{LiPF}_{6}, \mathrm{LiBF}_{4}\right.$ or $\left.\mathrm{LiClO}_{4}\right)$, and the lower chain carbonate solvent. Although the primary aim for recycling of lithium ion battery is to recover rare metals ( $\mathrm{Co}, \mathrm{Ni}, \mathrm{Mn}$, and $\mathrm{Li}$ ), the spent battery should be treated with the greatest care against flammable solvent, hazardous chemicals and container's corrosion.

Figure 3 shows a representative recycle process of spent lithium ion batteries, which is operated in a Japanese recycling company. The first step is roasting them for unsealing of the cell and carbonizing the organic components in electrolyte. Then, the residues are comminuted and sieved; the upper sieve followed by classification of $\mathrm{Fe}, \mathrm{Al}$, and $\mathrm{Cu}$, respectively, and the lower sieve subjected to acid leaching to remove carbonaceous material. The formed 
slag containing $\mathrm{Co}, \mathrm{Mn}$ and $\mathrm{Ni}$ is separated by three stages of solvent extraction to produce the respective sulphates. Each sulphate is reduced to metal by electrowinning process. $\mathrm{Li}_{2} \mathrm{CO}_{3}$ is recovered from the finally treated solution

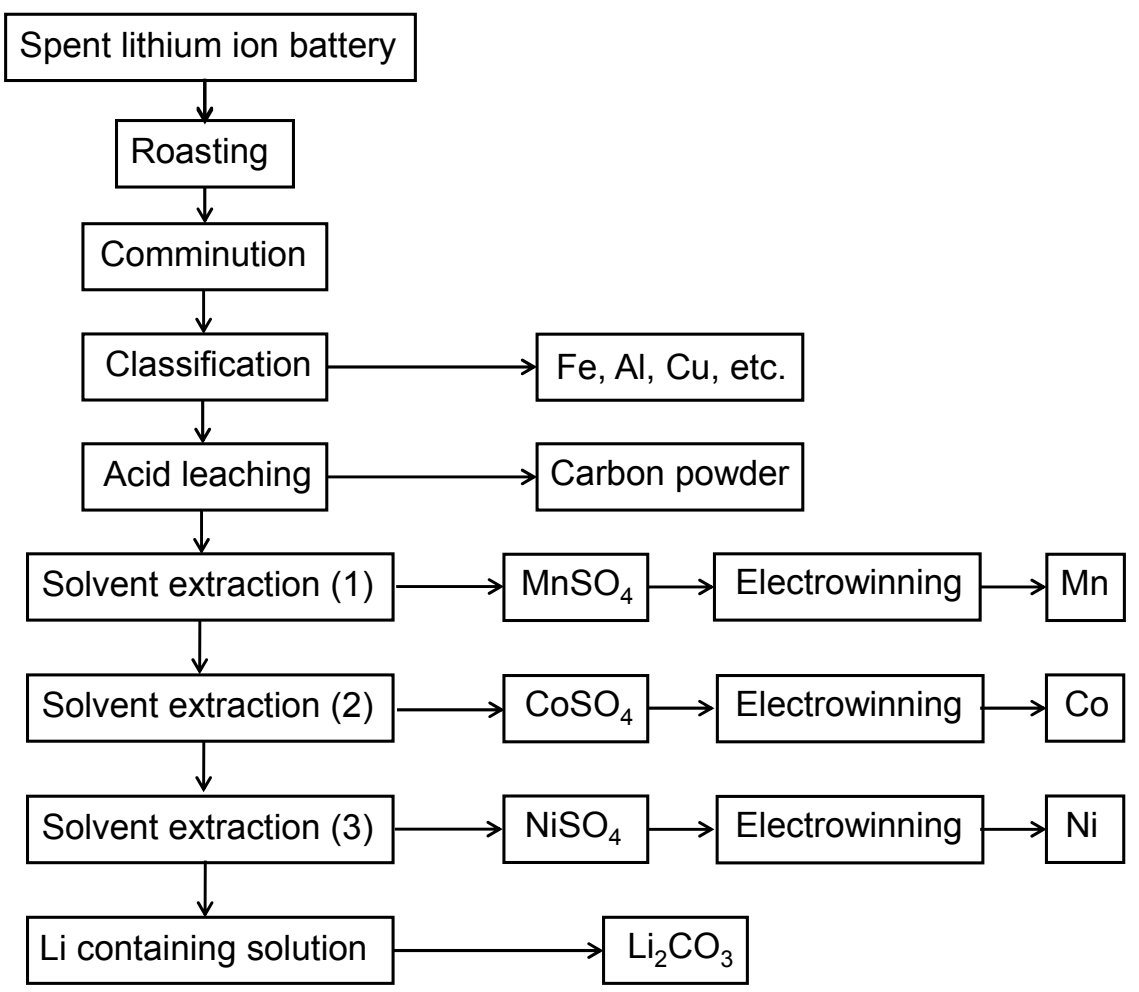

Figure 3: Recycle process of spent lithium ion batteries.

\subsection{Cemented carbide tool}

Cemented carbide provides many kinds of usages for cutting tools, dies and rolls, which need hardness, toughness and wear resistance in structural materials. The major constituent is tungsten carbide (WC: 80-95 wt\%) with Co binder. A small amount of metals $\mathrm{Ta}, \mathrm{Cr}, \mathrm{V}, \mathrm{Ti}$ is also added to depress the grain growth in sintering and to increase corrosion resistance of the products. All are so-called rare metals; particularly the cost of $\mathrm{W}$ is increasing year by year owing to the export restriction by China. Japanese companies have launched out for recovering tungsten from cemented carbide scraps a few years ago.

Conventional and novel recycle processes of tungsten from cemented carbide tools to APT (ammonium paratungstate: $5\left(\mathrm{NH}_{4}\right)_{2} \mathrm{O} \cdot 12 \mathrm{WO}_{3} \cdot 5 \mathrm{H}_{2} \mathrm{O}$ ) are compared in fig. 4. Conventional recycle process A implemented in EU and China, consists 
of the step 1 by roasting and alkali extraction, and the step 2 by formation of $\mathrm{CaWO}_{4}$ and acid decomposition. In contrast, the novel recycle process $\mathrm{B}$ developed by Sumitomo Electric Industries Group, Japan, adopts the step 1 by the sodium nitrate molten salt dissolution, and the step 2 by ion exchange adsorption and desorption. Both processes obtain $\mathrm{Na}_{2} \mathrm{WO}_{4}$ aqueous solution on the first step, and then form pure APT on the second step. The latter novel process is rather simple and requires low energy.

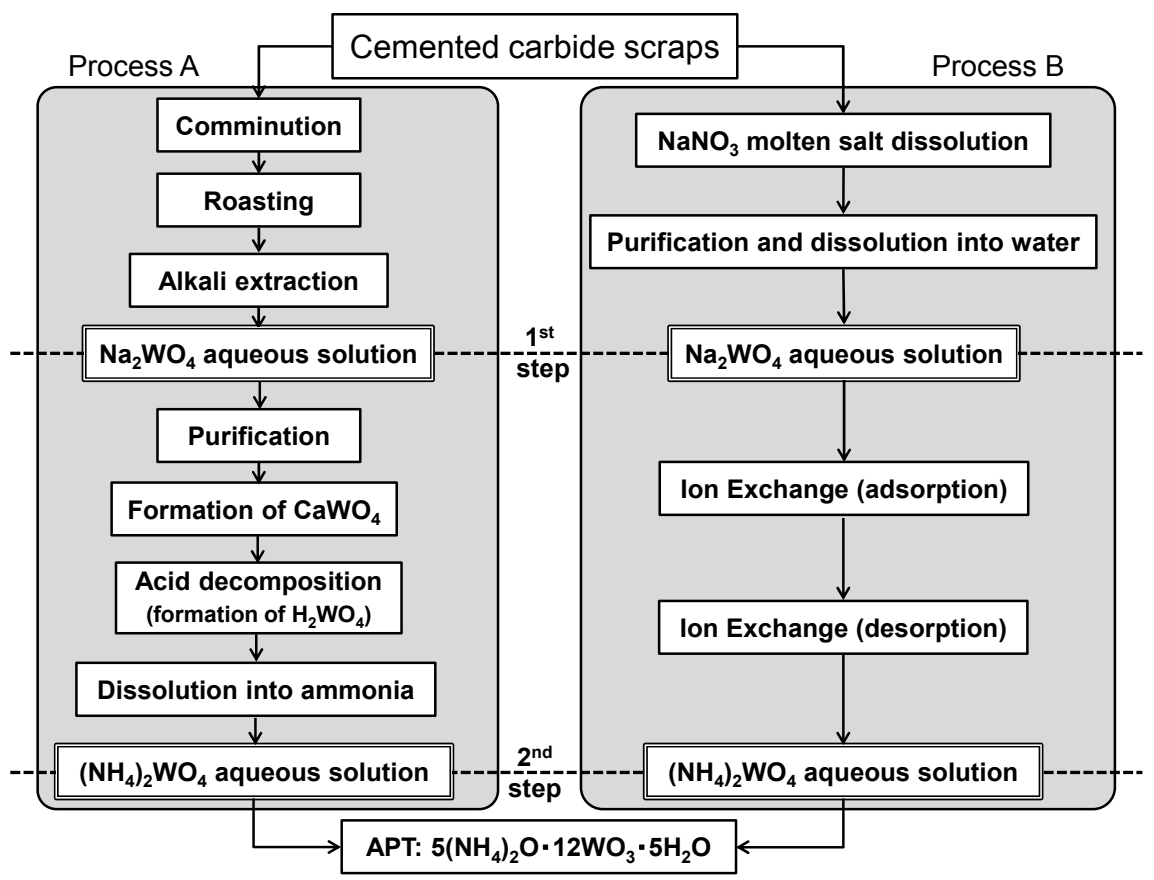

Figure 4: Recycle process of tungsten from cemented carbide tools to APT.

\section{Rare metal recovery complex for urban mining}

Efficient resource circulation of rare metals is one of the most important economic and political issues in the industrialized society like Japan. Rare metals such as $\mathrm{Pt}, \mathrm{Pd}, \mathrm{W}, \mathrm{Co}, \mathrm{Ni}, \mathrm{In}, \mathrm{Ta}, \mathrm{Ce}, \mathrm{Nd}, \mathrm{Dy}$, etc. in so-called "urban mine" should be collected separately, treated by mechanical, physical and chemical processes, and then reused as raw materials for materials production. This infrastructure in the materials vein system is referred to as "rare metal recovery complex" (RMRC), which promotes the artery system of the materials reproduction. The new technologies for rare metal recovery and the supply-chained flow system will be established by the collaboration of researchers, related companies, stakeholders, and local governments. 
Typical industrial waste categories from which rare metals are discharged, comprise (1) effluents from surface modification/plating, wastewater treatment and catalysts/supports industries, (2) e-wastes from electronic substrates, household electric appliances and many kinds of batteries, (3) automobiles, tools and structural materials (alloys, special alloy steels and advanced ceramics/glass) and (4) wastes or wastewaters from incinerators, melting furnaces and power stations. Such wastes in each category are individually collected according to the general and industrial wastes collection laws in Japan. Recent legislation of the recycling law of SHEA will accelerate the recycling rate of rare metal in SHEA. The new concept of RMRC is derived in order to collect the rare metals in all the municipal and industrial wastes, and give them mechanical, physical and chemical treatments in a systematic treatment plant, as shown in fig. 1 . We can expect the minimum use of energy and reagents required for the crushing/ shredding, separation and purification processes of rare metals.

\section{Conclusions}

The recent trend of rare metal recycling in e-wastes and industrial solid wastes in Japan is reviewed focusing on the present legal framework for recycling large home appliances and small household electrical appliances (SHEA). New collection system of SHEA has been legislated recently to promote the domestic recycling rate of e-wastes followed by mechanical and physical treatments for sorting, crushing and enrichment of rare metals in the companies approved by the government. Then, smelting and chemical treatments are required in order to recover high purity of rare metals from the enriched rare metals.

New technologies developed in Japan for recycling representative rare/noble metals $(\mathrm{Nd}, \mathrm{Au}, \mathrm{Ag}, \mathrm{Cu}, \mathrm{Ta}, \mathrm{Co}, \mathrm{Ni}, \mathrm{W}$, etc.) in neodymium magnet, printed circuit board, tantalum capacitor, lithium ion battery, and cemented carbide tool are introduced with an emphasis that the combination of such basic separation techniques is important for increasing the recovery efficiency of rare metals. In the near future, the conception of urban mining at rare metal recovery complex (RMRC) will contribute to the establishment of the multi-recovery system of rare metals with high efficiency and low cost as well as with low environmental loads.

\section{References}

[1] Takeda, O., Okabe, T.H. \& Umetsu, Y., Recovery of neodymium from a mixture of magnet scrap and other scrap. J. Alloys and Compounds, 408-412, pp. 387-390, 2006.

[2] Itakura, T., Sasai, R. \& Itoh, H., Resource recovery from Nd-Fe-B sintered magnet by hydrothermal treatment. J. Alloys and Compounds, 408-412, pp. 1382-1385, 2006.

[3] Matsuo, S., Kim, J-A., Murata, K., Dodbiba, G. \& Fujita, T., Evaluating the practical application of underwater explosion for recycling. Resources Processing, 58, pp. 52-58, 2011. 
14 Waste Management and The Environment VII

[4] Ono, H. \& Fujita, T., Tantalum recovery from printed circuit board by heat treatment. J. MMIJ, 127, pp. 519-525, 2011.

[5] Oki, T., Recovery of electric devices by kind from waste printed circuit boards based on a conception of strategic urban mining. Ceramics Japan, 49(1), pp. 30-34, 2014. 